were employed outside the home and none lived far from a clinic. Most of the children were in one parent families; few were from ethnic minority groups, although often the family consisted of a white mother and several coloured children.

The domiciliary immunisation service is centred on one immunisation nurse who has a commitment to the scheme and has the necessary attributes to be accepted both by the referring health visitor and the defaulting parents. An input is also required from health visitors and medical staff. The skills of the health visitor are used to identify suitable referrals and obtain parental consent. A doctor is needed in the home to assess medical fitness for immunisation and to give the injections, because all the referred children have a very poor clinic attendance record and the standard of child care is below the average for the district. Often an injection has to be deferred on medical grounds.

One particular nurse coordinates the domiciliary immunisation service, but the accompanying doctor is one of a group of interested community health doctors and community physicians. If the duty is shared in this way it cannot be considered to be a burden or a waste of professional time, and it is an effective way of obtaining first hand knowledge of the problems and health needs of the community.

I thank Dr Noel Preston, University of Manchester, for his help and encouragement in preparing this paper.

\section{References}

1 Butterworth A, Abbott JD, Simmons LE, et al. Diphtheria in the Manchester Area, 1967-71. Lancet 1974; ;ii: 1558 .

2 Galloway TMCL. Vaccination and immunization, managed by electronic data processing. Medical Officer 1966;116:58-60.

3 Newman CPStJ. Immunization in childhood and computer scheme participation. Public Health 1983;97:208-13.

4 Anonymous. Failure to vaccinate [Editorial]. Lancet 1983;ii: 1343

(Accepted 31 August 1984

\title{
$\beta$ Blockers after myocardial infarction: have trials changed practice?
}

\author{
N S BABER， D G JULIAN， J A LEWIS， G ROSE
}

\section{Abstract}

A survey of British consultant cardiologists was carried out to elicit their current practices when prescribing long term $\beta$ blockers after myocardial infarction. Sixty $(72 \%)$ of the respondents reported that they used $\beta$ blockers prophylactically even in the absence of any other indications; the details of their stated policies, however, varied considerably.

The favourable evidence of clinical trials in this indication appears to have been assimilated into hospital practice.

\section{Introduction}

Clinical trials have agreed widely that the long term prophylactic use of $\beta$ adrenergic blocking drugs after myocardial infarction reduces mortality, ${ }^{1.5}$ but even though the evidence is probably accepted by most practising physicians, disagreement continues on how it should be translated into clinical practice. Is the reduction in mortality large enough to justify the cost in both human and economic terms? Is $\beta$ blockade only worth while in certain categories of patient? How long is long term? To gain some insight into the effects of this recent research we carried out a simple survey among a sample of British cardiologists to assess their current clinical practice. In addition, we used this opportunity to investigate the feasibility of a clinical trial to establish the effect of withdrawing $\beta$ blockade after one or two years' treatment after myocardial infarction (a "stopping trial").

International Medical Affairs Department, Pharmaceuticals Division, Imperial Chemical Industries PLC, Macclesfield, Cheshire SK10 4TG

N S BABER, MB, MRCP, medical adviser

J A LEWIS, DIPSTAT, FIS, division chief statistician

Department of Cardiology, Freeman Hospital, Newcastle upon Tyne NE7 7DN D G JULIAN, MD, FRCP, professor of cardiology

London School of Hygiene and Tropical Medicine, London WC1E 7HT

G ROSE, FRCP, FFCM, professor of epidemiology

Correspondence to: Dr N S Baber.

\section{Methods}

A random sample of 100 cardiologists was drawn from a list of all British consultant cardiologists. Attempts were made to exclude those not in clinical practice. A questionnaire was sent to each member of the sample. Nonresponders were contacted again, first by letter and then by telephone. Incomplete or unclear forms were also corrected whenever possible after further contact by letter or telephone. Tables I-V show the questions asked. They were intended to be clear and simple and to relate to a limited number of important issues.

\section{Results}

Of the 100 doctors surveyed, six were found not to be practising cardiologists, three stated that they did not have postinfarction patients under their care, four refused to complete the form, and four did not respond in any way. There were thus 83 questionnaires for analysis from the 91 cardiologists supposedly eligible for the survey; 75 were complete.

Tables I-V summarise the responses to the questions. Table I shows that $60(72 \%)$ of the respondents reported that they used $\beta$ blockers prophylactically after myocardial infarction, even when other indications for $\beta$ blockade were absent. Roughly half of these reckoned to treat all patients who did not have a contraindication to $\beta$ blockade. The remaining half reported that they attempted to select patients at high risk. Opinion was about evenly divided on the question of an upper age limit for prophylactic treatment (table II). Those who set an age limit nearly all chose 65 or 70 . Most reckoned to treat patients prophylactically for over a year, and nearly half for more than two years (table III).

TABLE I-Responses to question: "In a patient discharged from hospital following confirmed myocardial infarction, my current practice is to prescribe long term $\beta$ blocking drugs as follows"

\begin{tabular}{lc}
\hline Possible replies & $\begin{array}{c}\text { No (\%) of doctors } \\
\text { choosing reply }\end{array}$ \\
\hline (1) To treat only those patients with other indications for $\beta$ blockade & $23(28)$ \\
$\quad$ (such as hypertension or angina) & $28(34)$ \\
(2) To treat prophylactically all patients who do not have a & contraindication to $\beta$ blockade \\
(3) To treat prophytactically only those patients who are at high risk of & $30(36)$ \\
$\quad$ death or reinfarction (plus those with other indications as in (1) above) & $2(2)$ \\
(4) Other prophylactic use. Please specify & $60(72)$ \\
Total prophylactic use &
\end{tabular}

*"Younger patients who may be at increased risk," and "Policy (3) together with patients withou angina but with a positive post myocardial infarction exercise test. 
Table IV summarises the proportion of patients treated with $\beta$ blockers after myocardial infarction by the cardiologists in our sample. The overall proportion seemed to lie in the interval 25 to $50 \%$. (To be certain of this we would need to know how many patients each cardiologist treated.) Interestingly, seven respondents reckoned to treat three quarters or more of their patients with $\beta$ blockers. These seven all belonged to the group who treated prophylactically all patients except those with contraindications to $\beta$ blockade.

About one third of the sample expressed interest in taking part in a over 2500 patients a year. stopping trial (table V); they estimated that they would contribute, in total,

of general practitioners. Cardiologists' practice could well differ from their own perception of it as reflected in our survey. Alternatively the explanation of the apparent discrepancy might lie with the cardiologists not controlling long term after care. These possibilities deserve further study.

The difference of opinions expressed about the duration of prophylaxis (table III) and the willingness of a third of respondents to take part in a "stopping trial" indicate the uncertainty about this issue. If survivors of myocardial infarction were to be treated with $\beta$ blockers for one year, then randomised to continuation or stopping

\begin{tabular}{|c|c|}
\hline & $\begin{array}{l}\text { No }(\%)^{\star} \text { of } \\
\text { cardiologists }\end{array}$ \\
\hline $\begin{array}{l}\text { Upper age limit (years): } \\
65 \\
70 \\
75\end{array}$ & $\begin{array}{c}10(17) \\
15(26) \\
1(2)\end{array}$ \\
\hline $\begin{array}{l}\text { Setting a limit: } \\
\text { Total to do so } \\
\text { Total not to do so } \\
\text { Question unanswered }\end{array}$ & $\begin{array}{c}26(45) \\
32(55) \\
2\end{array}$ \\
\hline $\begin{array}{l}\text { Total who use } \beta \text { blockers } \\
\text { prophylactically }\end{array}$ & 60 \\
\hline
\end{tabular}

^Proportion of total (58) who answered the question.

TABLE III-Responses to question: "When you use $\beta$ blockers prophylactically for how long do you continue treatment?"

\begin{tabular}{lc}
\hline Duration (months) & $\begin{array}{c}\text { No }(\%)^{\star} \text { of } \\
\text { cardiologists }\end{array}$ \\
\hline$\leq 12$ & $10(18)$ \\
$13-24$ & $21(37)$ \\
$>24$ & $26(46)$
\end{tabular}

^Proportion of total (57) who answered question

TABLE IV-Responses to question: "Regardless of the selection criteria chosen, what proportion of post myocardial infarction patients do you treat with $\beta$ blockers?"

\begin{tabular}{lc}
\hline Proportion (\%) & $\begin{array}{c}\text { No (\%)* of } \\
\text { cardiologists }\end{array}$ \\
\hline$<25$ & $19(23)$ \\
$25-49$ & $35(43)$ \\
$50-74$ & $21(26)$ \\
$\geqslant 75$ & $7(8 \cdot 5)$ \\
\hline
\end{tabular}

^Proportion of total (82) who answered question

\section{Discussion}

The original list of consultant cardiologists from which the sample was drawn consisted of physicians from teaching and nonteaching hospitals. The size of our sample (about a quarter of the consultant cardiologists in the United Kingdom) and the high response to our survey ensured that it adequately represented the views of the British cardiological profession. Our results suggest that the evidence from clinical trials in favour of oral $\beta$ blockade after myocardial infarction has been generally accepted, not only in theory but also in hospital practice. Is this evidence corroborated by an increase in prescriptions for $\beta$ blockers after discharge? Reliable figures are difficult to obtain. Such information, however, as can be gleaned from marketing surveys does not suggest an increasing tendency to prescribe $\beta$ blockers for ischaemic heart disease by general practitioners over the past few years (Intercontinental Medical Statistics Ltd, Medical Data Index, 1979-84). This is also hinted at by Hampton. ${ }^{6}$ If this is true, there would seem to be a discrepancy between the intention of cardiologists and the practice

\begin{tabular}{|c|c|}
\hline Possible replies & $\begin{array}{c}\text { No (\%) of } \\
\text { cardiologists }\end{array}$ \\
\hline $\begin{array}{l}\text { No } \\
\text { Yes } \\
\text { Uncertain }\end{array}$ & $\begin{array}{c}56(67) \\
26^{\star}(31) \\
1(1)\end{array}$ \\
\hline
\end{tabular}

of treatment, and followed up for a further two years, it would seem reasonable to try to detect a $20 \%$ difference in mortality-similar to the confirmed benefit of $\beta$ blockade. The practolol and timolol trials and the $\beta$ blocker heart attack (BHAT) trial with propranolol suggest that this would represent a change in one to three year mortality from $6 \%$ to $4 \cdot 8 \%$. To have a reasonable $(95 \%)$ chance of detecting this difference at the $5 \%$ level $(2 p<0.05)$ would require about 15000 patients. In view of our doubts about the full realisation of the confirmed benefits of $\beta$ blockers after myocardial infarction, despite a favourable consensus of cardiologists' opinions and their stated practice, to embark on a major undertaking to answer this secondary question does not seem reasonable. (The question might have been answered at far less cost if it had been incorporated in the designs of the larger original trials.)

\section{References}

1 Chamberlain DA. Beta adrenoceptor antagonists after myocardial infarction-where are we now? Br Heart $\mathcal{O}$ 1983;49:105-110. beta-adrenoceptor blockers in post-myocardial infarction patients. Am Heart f 1982;104:1395-9 61 .

4 Yusuf S, Peto R, Lewis J, Collins R, Sleight P. Beta-blockade during and after myocardial infarction: an overview of the randomised trials. Prog Cardiovasc $D$ is (in press). Baber NS, Lewis JA. Confidence in results of beta-blocker post-infarction trials. Br Med J
1982;284:1749-50.

6 Hampton JR. The end of clinical freedom. BrMed f 1983;287:1237-8.

(Accepted 29 August 1984)

Is it still believed that "drumsticks" on the nuclei of polymorphonuclear leucocytes indicate an extra $X$ chromosome (XXY in males or Klinefelter's syndrome)?

Characteristic "drumstick" sex chromatin bodies occurring on the nuclei of polymorphonuclear leucocytes do indicate the presence of a condensed, late replicating $\mathrm{X}$ chromosome, but not necessarily an "extra" $\mathrm{X}$ chromosome. The maximum number of sex chromatin bodies in any one cell is one less than the total $\mathrm{X}$ chromosome complement; thus normal males and Turner females show none, normal females and XXY Klinefelter males one, and XXX females two. The low frequency of drumsticks and confusion with other nuclear tags make analysis difficult, and numerical and structural abnormalities may be missed. The evaluation of Barr bodies and fluorescent $\mathrm{Y}$ bodies in buccal epithelial cells is a better method, but sex chromatin tests are now little used. A much more satisfactory and reliable assessment of the sex chromosomes may be obtained from a full chromosomal analysis.-M A C RIDLER, consultant psychogeneticist, St Albans.
Staessen J, Bulpitt C, Cattaert A, Fagard R, Vanhees L, Amery A. Secondary prevention with 